\title{
Pemilah Benda Berdasarkan Warna Menggunakan Sensor Warna TCS3200
}

\author{
Marlindia Ike Sari ${ }^{1}$, Rini Handayani ${ }^{2}$, Simon Siregar ${ }^{3}$, Bagus Isnu ${ }^{4}$ \\ ${ }^{1,2,3,4}$ D3 Teknik Komputer, Fakultas Ilmu Terapan, Universitas Telkom \\ Jl. Telekomunikasi no 1, Bandung \\ ike@tass.telkomuniversity.ac.id ${ }^{1}$, rinihandayani@tass.telkomuniversity.ac.id ${ }^{2}$, \\ simon.siregar@tass.telkomuniversity.ac.id ${ }^{3}$, smilersmiler251@gmail.com ${ }^{4}$
}

\begin{abstract}
Abstrak - Penelitian ini mendesain sebuah protoype alat pemilah barang berdasarkan warna menggunakan sensor warna TCS3200. Sistem mengindentifikasi 5 warna yaitu warna merah, hijau, biru, putih, dan hitam. Lima motor digunakan untuk untuk setiap wrna. Setiap motor diaktifkan oleh warna tertentu. Satu motor DC juga digunakan untuk menggerakan conveyor yang digunakan untuk meletakkan benda yang akan diidentifikasi oleh sensor warna. Pada penelitian ini disusun desain mekanik dan elektronik untuk pemilah barang menggunakan sensor warna TCS3200, motor driver dan motor DC. Alat pemilah ini dapat memilah barang dengan arna merah, hijau, biru, hitam, dan putih. Hasil pengujian menunjukkan bahwa warna objek dapat diidentifikasi oleh sensor warna dengan kisaran warna yang ditentukan dan mengaktifkan motor servo tertentu
\end{abstract}

Kata Kunci: motor, pemilah, sensor warna, TCS3200

\section{Pendahuluan}

Pemilah barang/benda jamak dilakukan di industri. Pemilahan barang dapat dilakukan dengan mengelompokkan jenis, warna, atau bentuk barang. Sistem pemilahan dapat dilakukan dengan sistem manual menggunakan tenaga manusia, sistem barcode, ataupun otomatisasi dengan mesin.

Sistem pemilahan berdasarkan warna merupakan hal yang dapat dikembangkan dengan berbagai metode. Untuk pendeteksian warna dapat memanfaatkan pantulan cahaya yang dipantulkan oleh benda yang terpapar cahaya putih. Dengan pemanfaatan pemantulan cahaya ini, deteksi warna suatu benda dapat dilakukan dengan sebuah alat yang bisa menangkap pantulan cahaya dan mendefinisikan warna yang ditangkap. Pada penelitian [1] telah dibangun purwarupa pemilahan barang menggunakan sensor warna TCS230 untuk mendeteksi warna dan digunakan PLC (Progammable Logic Control) sebagai sistem penggeraknya. Warna yang dideteksi yaitu warna hijau, merah, dan biru. Pada penelitian [2] telah dibangun purwarupa alat penyortir warna dengan TCS230 dan menggunakan 2 conveyor untuk sistem penggerak dan pengumpulnya. Conveyor pertama sebagai penggerak benda, dan conveyor kedua sebagai penggerak tempat penampungan barang berdasarkan kelompok warna. Kelompok warna yang dideteksi adalah warna merah, biru, dan hijau. Pada penelitian [3] memanfaatkan pengolahan citra dalam pemilahan warna, dan menggunakan lengan robot untuk sistem mekaniknya. Pada penelitian [4] pemilahan warna menggunakan sensor warna digunakan untuk pemilahan sepatu kulit. Pada penelitian [5] pemilahan warna menggunakan mesin sortir optik menggunakan sensor warna.

Dari penelitian-penelitian yang dijelaskan sebelumnya, penelitian ini menambahkan jenis wana yang dideteksi, dan menerapkan desain mekanik model lain. Penelitian ini akan membahas mengenai pembangunan purwarupa sistem pemilahan benda/barang berdasarkan warna, yaitu warna hitam, putih, merah, hijau, dan biru. Sistem ini menggunakan sensor warna untuk pembaca warna. Warna yang dibaca berdasarkan format warna RGB (Red, Green, Blue). Benda akan

TELKA, Vol.4, No.2, November 2018, pp. 85 90

ISSN (e): 2540-9123

ISSN (p): 2502-1982 
dideteksi dan dikelompokkan sesuai kelompok warna. Pendeteksian ini akan mengaktifkan motor dan yang menjadi pintu untuk masing-masing warna. Sistem mekaniknya menggunakan 1 conveyor dan 5 motor yang setiap motor untuk gate satu warna.

Pemanfaatan Sensor TCS3200 ini berdasarkan penggunaan komponen photodiode yang ada pada sensor ini. Hal ini berdasarkan penelitian [6][7] dijelaskan tentang respon photodiode dan photo detector terhadap spectrum cahaya tampak.

\section{Desain dan Implementasi Sistem}

Pada penelitian ini, pembangunan sistemnya dapat digambarkan dengan diagram blok pada Gambar 1.

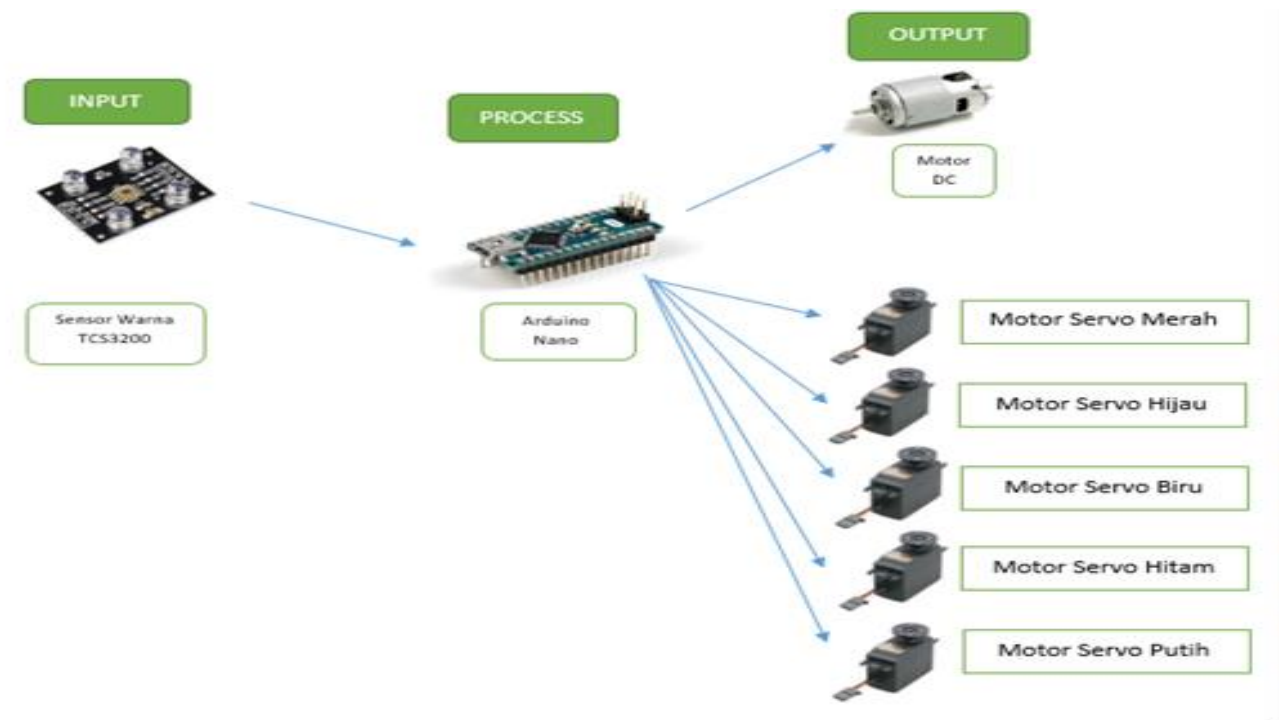

Gambar 1. Diagram Blok Sistem

Seperti yang ditunjukkan pada Gambar 1, sistem ini menggunakan sensor TCS3200 untuk identifikasi warna pada input, dan data dikirim ke pemroses yaitu Arduino Nano, data diolah dan diidentifikasi warnanya. Pada output terdiri dari 5 motor. Setiap motor akan diaktifkan oleh hasil identifikasi warna. Jika warna merah dikenali, maka motor untuk gate warna merah akan bergerak dan membuka gate, sehingga benda akan masuk ke penampungan warna merah. Desain mekanik dan penempatan tiap komponen ditunjukkan pada Gambar 2 dan Gambar 3.

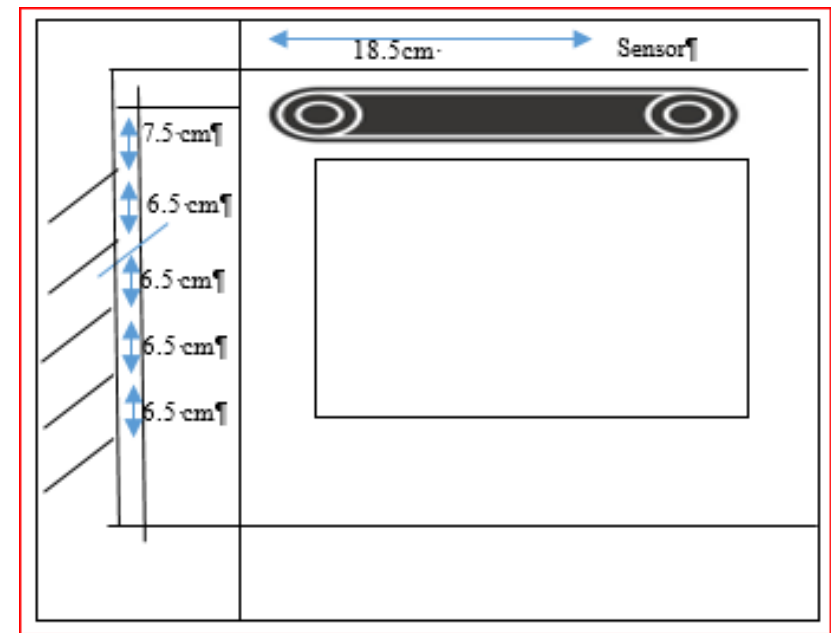

Gambar 2 Desain Mekanik Sistem 
Desain mekanik dibuat agar benda yang disortir dapat terbaca oleh sensor warna. Benda berada di conveyor dengan penyetingan kecepatan conveyor sehingga benda masih dapat dibaca oleh sensor warna. Untuk menstabilkan pembacaan warna oleh sensor, sensor berada di area tertutup atau diberi cover agar pembacaan lebih akurat. Setelah warna terdeteksi, maka gate yang sesuai akan terbuka, dan benda jatuh pada gate yang terbuka dan masuk ke penampungan yang sesuai dengan warna. Visualisasi desain mekanik ditunjukkan pada Gambar 3.

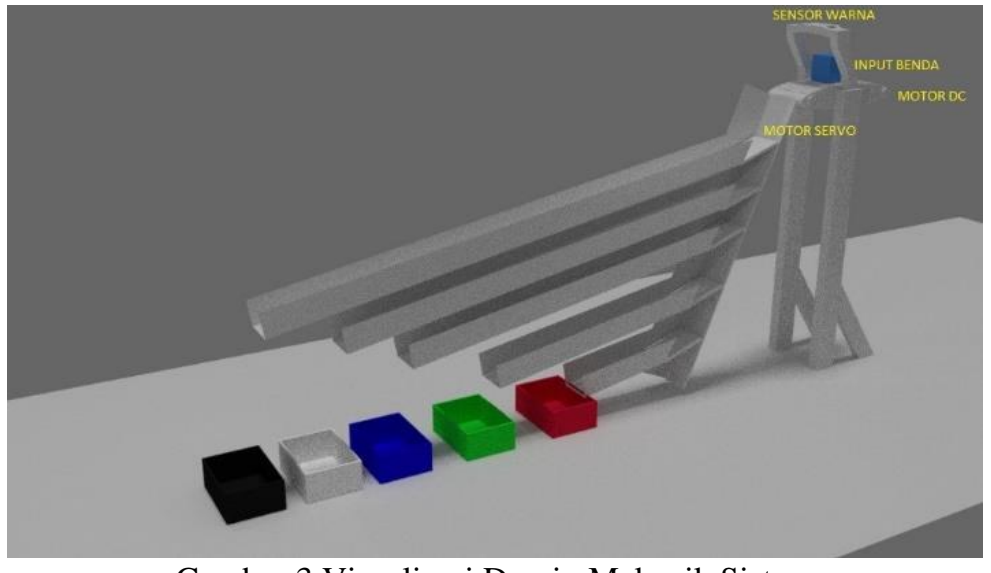

Gambar 3 Visualisasi Desain Mekanik Sistem

Untuk alur pendeteksian warna, algoritma pembacaan ditunjukkan pada Gambar 4. Identifikasi warna dilakukan dengan penentuan range nilai setiap warna. Warna yang diidentifikasi yaitu warna merah, biru, hijau, biru, putih dan hitam.

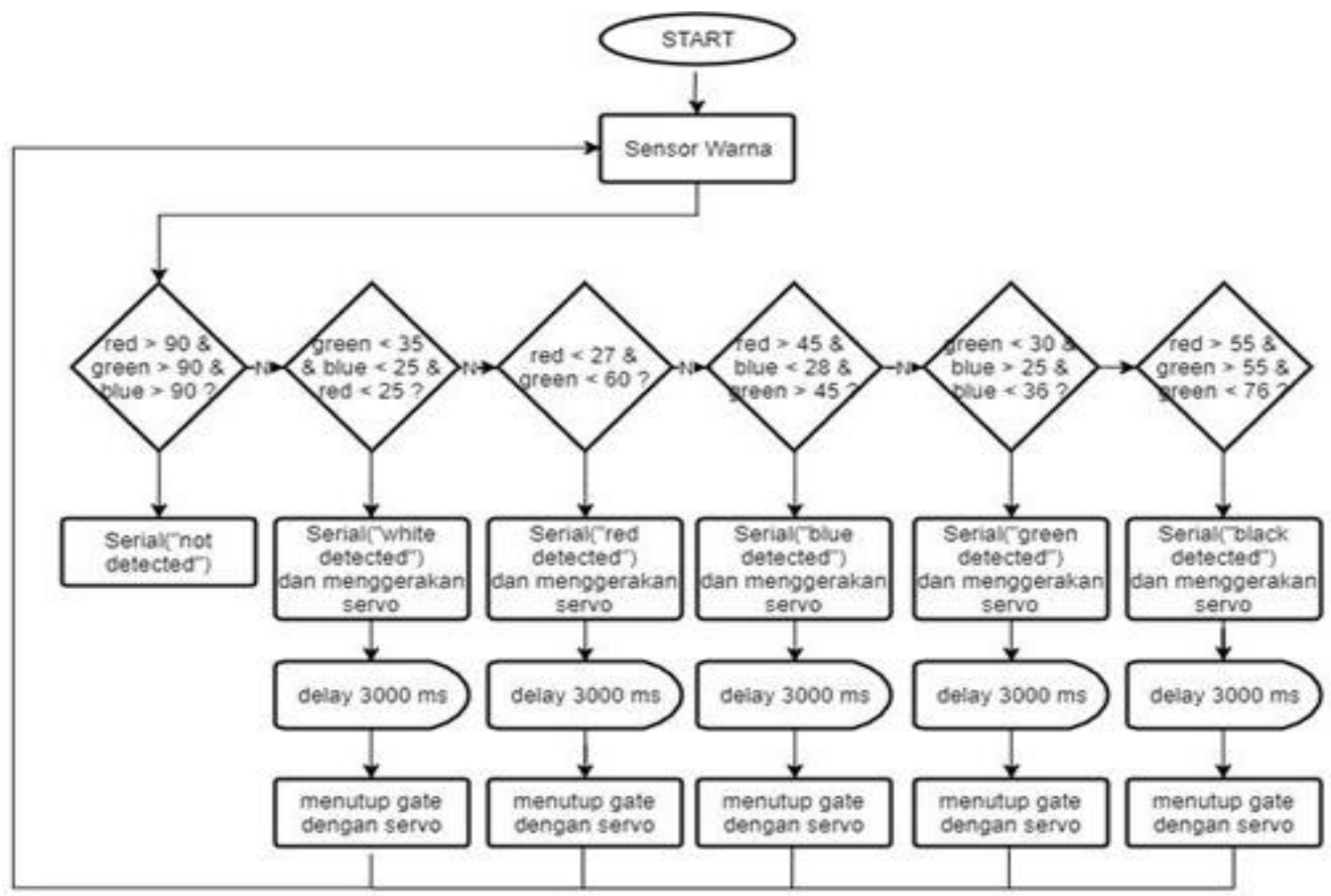

Gambar 4. Flowchart Sistem

ISSN (e): 2540-9123 


\section{Hasil dan Pembahasan}

\subsection{Pengujian Warna}

Pengujian warna dilakukan untuk pendeteksian warna benda. Warna yang dideteksi adalah warna merah, hijau, biru, putih, dan hitam. Pengujian ini dilakukan untuk penentuan range nilai setiap warna benda yang dideteksi oleh sensor warna.

Hasil pengujian pendeteksian warna pada sensor warna ini menunjukkan nilai yang berbedabeda untuk setiap jenis warna yang sama. Kisaran nilai warna yang ditunjukkan pada Tabel 1 merupakan hasil dari pengujian warna yang digunakan sebagai batasan untuk menggerakan motor pada gate.

Tabel 1. Hasi Pengujian Warna

\begin{tabular}{cccccc}
\hline $\begin{array}{c}\text { Nilai } \\
\text { Pengujian }\end{array}$ & $\begin{array}{c}\text { Pengujian } \\
\text { Merah }\end{array}$ & $\begin{array}{c}\text { Pengujian } \\
\text { Hijau }\end{array}$ & $\begin{array}{c}\text { Pengujian } \\
\text { Biru }\end{array}$ & $\begin{array}{c}\text { Pengujian } \\
\text { Putih }\end{array}$ & $\begin{array}{c}\text { Pengujian } \\
\text { Hitam }\end{array}$ \\
\hline$R$ & $9-10$ & 17 & $38-39$ & 8 & $52-55$ \\
$G$ & $38-39$ & $12-13$ & $27-30$ & $8-9$ & $50-63$ \\
$B$ & $27-28$ & $20-21$ & $10-11$ & 6 & $43-45$ \\
\hline
\end{tabular}

Berdasarkan pada Tabel 1, hasil yang didapatkan pada pengujian sensor warna adalah sebagai berikut:

- Warna merah lebih kecil pada nilai pengujian $\mathrm{R}$, dengan nilai 9-10 dari pada nilai pengujian $\mathrm{G}$ dan $\mathrm{B}$.

- Warna hijau lebih kecil pada nilai pengujian G, dengan nilai 12-13 daripada nilai pengujian $\mathrm{R}$ dan $\mathrm{B}$.

- Warna biru lebih kecil pada nilai pengujian $\mathrm{B}$, dengan nilai 10-11 daripada nilai pengujian $\mathrm{R}$ dan $\mathrm{G}$.

- Warna putih bernilai kecil pada pengujian $R G B$, dengan nilai $R=8, G=8-9, B=6$.

- Warna hitam bernilai besar pada pengujian $\mathrm{RGB}$, dengan nilai $\mathrm{R}=52-55, \mathrm{G}=50-63, \mathrm{~B}=$ 43-45. Warna hitam bernilai besar pada pengujian $R G B$, dengan nilai $\mathrm{R}=52-55, \mathrm{G}=50$ $63, \mathrm{~B}=43-45$.

Pengujian juga dilakukan terhadap intensitas cahaya yang diterima oleh snsor warna saat kondisi tidak ada benda yang terdeteksi.

\begin{tabular}{|c|c|c|c|}
\hline $\begin{array}{l}\text { Pengujian } \\
\text { Sensor }\end{array}$ & $\mathbf{R}$ & $\mathbf{G}$ & B \\
\hline Tertutup & $60-61$ & $69-71$ & 53-54 \\
\hline Terbuka & $49-50$ & $56-57$ & $44-45$ \\
\hline
\end{tabular}

Berdasarkan Tabel 2 Hasil nilai intensitas cahaya yang diterima sensor warna pada saat mekanik tertutup meningkat karena cahaya pada sekitar sensor warna menjadi gelap, nilai intensitas cahaya menurun saat cahaya pada sekitar sensor warna menjadi terang. 


\subsection{Pengujian Motor Servo pada Gate}
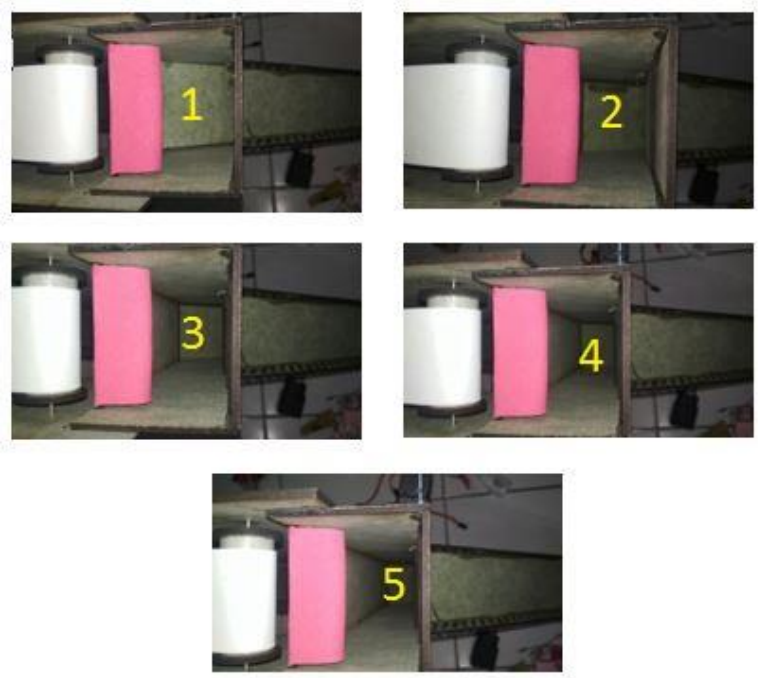

Gambar 5. Hasil Implementasi Gate untuk 5 Warna

Gambar 5 merupakan pengujian terhadap 5 gate. Gate 1 untuk warna merah, gate 2 untuk warna hijau, gate 3 untuk warna biru, gate 4 untuk warna putih, dan gate 5 untuk warna hitam. Pengujian dilakukan dengan meletakkan benda di depan sensor, sehingga gate yang sesuai warna benda tersebut akan terbuka setelah terdeteksi warna merah, hijau, biru, putih, dan hitam.

Tabel 3. Pengujian Gate

\begin{tabular}{cccc}
\hline $\begin{array}{c}\text { Sensor mendeteksi } \\
\text { warna benda }\end{array}$ & $\begin{array}{c}\text { Gate } \\
\text { Terbuka }\end{array}$ & Posisi & $\begin{array}{c}\text { Tegangan } \\
\text { Dibutuhkan }\end{array}$ \\
\hline Merah & 1 & $45^{\circ}$ & $4,8 \mathrm{~V}$ \\
Hijau & 2 & $45^{\circ}$ & $4,8 \mathrm{~V}$ \\
Biru & 3 & $45^{\circ}$ & $4,8 \mathrm{~V}$ \\
Putih & 4 & $45^{\circ}$ & $4,8 \mathrm{~V}$ \\
Hitam & 5 & $45^{\circ}$ & $4,8 \mathrm{~V}$ \\
\hline
\end{tabular}

Berdasarkan hasil pengujian pada Tabel 3, respon motor servo dapat membuka ketika terdeteksi warna yang sesuai.

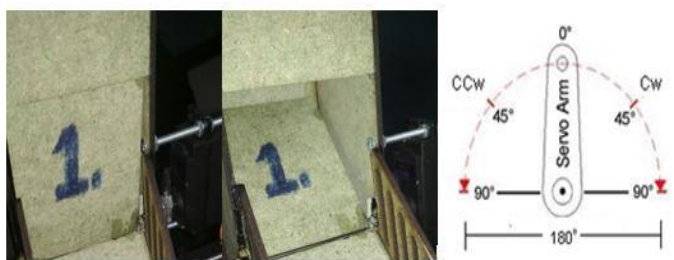

Gambar 6. Sudut Motor Servo Pada Gate

Pada Gambar 6, sudut yang telah diatur pada motor servo adalah $45^{\circ}$. Sudut tersebut akan digunakan sebagai sudut optimal gate pada saat benda jatuh menuju ke penampungan.

\section{Kesimpulan}

Dari hasil desain dan pembangunan sistem alat sortir berdasarkan warna, telah berhasil diterapkan dengan menggunakan sensor warna TCS3200 dan 5 motor servo untuk tempat pemilah dan motor dc untuk conveyor barang. Warna yang berhasil dipilah yaitu warna merah, hijau, biru, putih, dan hitam. Untuk penelitian berikutnya akan dikembang sistem monitoring dan benda yang disortir, dan jenis warna yang dideteksi lebih lebih bervariasi, seperti penambahan warna sekunder kuning, magenta, cyan. 


\section{Daftar Pustaka}

[1] W. Euis, H. Witarsa, M. Verdian, and D. Yuniarti, "Prototipe Penyortir Barang Berdasarkan Warna , Bentuk Dan Tinggi Berbasis Programmable Logic Controller ( Plc ) Dengan Penggerak Sistem Pneumatic," vol. 1, no. 2, 2014.

[2] C. K. Kunhimohammed, M. S. K. K, S. Sahna, M. S. Gokul, and S. U. Abdulla, "Automatic Color Sorting Machine Using TCS230 Color Sensor And PIC Microcontroller," vol. 2, no. 2, pp. 33-38, 2015.

[3] Y. Jia, G. Yang, and J. Saniie, "Real-time color-based sorting robotic arm system," IEEE Int. Conf. Electro Inf. Technol., pp. 354-358, 2017.

[4] M. Jawahar, K. C. Divya, and V. Thankaiselvan, "Sensor based color sorting system for leather shoe components," Proc. 2017 3rd IEEE Int. Conf. Sensing, Signal Process. Secur. ICSSS 2017, pp. 296-300, 2017.

[5] T. Henry, Laurence, Ishak, and F. Jie, "Design and construction of color sensor based optical sorting machine," Proc. 2017 5th Int. Conf. Instrumentation, Control. Autom. ICA 2017, pp. 36-40, 2017.

[6] A. Wachowiak, S. Slesazeck, P. Jordan, J. Holz, and T. Mikolajick, "New color sensor concept based on single spectral tunable photodiode," Eur. Solid-State Device Res. Conf., pp. 127-130, 2013.

[7] M. Moghavvemi, S. S. Jamuar, E. H. Gan, and Y. C. Yap, "Design of low cost flexible RGB color sensor," 2012 Int. Conf. Informatics, Electron. Vision, ICIEV 2012, pp. 1158-1162, 2012. 